\title{
Kilounit per Liter
}

National Cancer Institute

\section{Source}

National Cancer Institute. Kilounit per Liter. NCI Thesaurus. Code C67385.

An arbitrary unit of substance concentration equal to the concentration at which one liter of mixture contains one thousand units of a substance. 